\title{
ANALISIS DAN INTEGRASI KEARIFAN LOCAL LUBUK LARANGAN TANTANG SAKTI DALAM PEMBELAJARAN SAINS
}

\author{
Jufrida $^{1}$, Fibrika Rahmat Basuki ${ }^{2}$ Anggun Destinanda ${ }^{3}$ \\ ${ }^{1,2,3}$ Prodi Pendidikan Fisika UniversitasJambi, Jambi, Indonesia \\ Corresponding author email: jufrida_66@yahoo.com
}

\section{Info Artikel}

Diterima:

06 Juni 2020

Disetujui:

20 Juni 2020

Dipublikasikan:

30 Juni 2020

\begin{abstract}
Abstrak:
Penelitian ini bertujuan menganalisis konsep sains yang terdapat pada kearifan lokal lubuk larangan tantang sakti serta mengintegrasikan kearifan lokal dalam pembelelajaran sains. Penelitian ini merupakan penelitian deskriptif kualitatif. Subjek dalam penelitian ini yaitu tokoh masyarakat Desa Suban dan ahli pendidikan sains. Pengumpulan data dilakukan melalui wawancara dan dokumentasi. Data dianalisis secara deskriptif. Lubuk Larangan Tantang Sakti merupakan kearifan lokal masyrakat Desa Suban dalam menjaga kelestarian ikan dan daerah aliran sungai. Lubuk Larangan adalah daerah aliran sungai yang telah disepakati oleh masyarakat dan lembaga adat yang mengatur larangan menangkap ikan di sungai tersebut. Lubuk larangan Tantang sakti menjadi tempat konservasi ikan kapiat/lampam (Barbonymus schwanenfeldii). Lubuk larangan dapat diintegrasikan dalam pembelajaran sains pada topik konservasi lingkungan, ekosistem, dan fluida.
\end{abstract}

Kata Kunci: Kearifan lokal, lubuk larangan, pembelajaran sains

\begin{abstract}
:
The research aims to analyze the concept of science that was found in local wisdom, and integrate local wisdom into the science of the sciences. This research is a qualitative descriptive study. The subject in this study was the community figure of Suban Village and science education expert. Data collection was done through interviews and documentation. Data was analyzed descriptively. Lubuk Larangan "Tantang Sakti" is the local wisdom of Suban village in preserving of fish and watershed. Lubuk Larangan is a watershed area that has been agreed by the community and traditional institutions that regulate the prohibition of fishing in the river. Lubuk Larangan "Tantang Sakti" becomes a conservation area for kapiat/lampam fish (Barbonymus schwanenfeldii). Lubuk Larangan can be integrated in science learning on the topics of environmental conservation, ecosystems, and fluids.
\end{abstract}

Keyword: Local wisdom, lubuk larangan, science learning

Copyright $\odot 2020$ Edufisika: Jurnal Pendidikan Fisika

\section{Pendahuluan}

Indonesia merupakan negara yang kaya akan budaya dan kearifan local. Bentuk kearifan local disetiap daerah sangat beragam. Kearifan lokal merupakan sistem nilai dan norma yang dipegang masyarakat dalam berinteraksi dengan lingkungan sekitar (Agung, 
2015). Setiap daerah memiliki ciri khas tersendiri di setiap kearifan lokal dan kebudayaan yang dimilikinya. Nilai kebudayaan berupa tradisi masyarakat tersebutlah yang membantu melestarikan kearifan lokal yang ada dilingkungan masyarakat sekitar. Setiap masyarakat juga memiliki sumber daya alam yang bermanfaat untuk pengembangan perekonamian. Kearifan lokal terbukti menunjukan suatu identitas budaya dalam tiap daerah yang berupa pengetahuan, ide-ide yang setiap orangnya memiliki keuntungan untuk mencari mata pencarian (Chusorn, 2014).

Setiap daerah memiliki identitas dan kearifan lokal sendiri sebagai kebijaksanaan universal yang dimiliki bersama (Mungmachoun, 2012). Kearifan lokal adalah solusi untuk masalah lingkungan, karena terdiri dari nilai-nilai yang dapat menyeimbangkan dan melestarikan lingkungan (Fahrianoor et al, 2013). Seperti dikatakan Tamalene et al (2014) kearifan lokal memperkuat hubungan antara manusia dan alam. Hubungan mengingatkan kesadaran masyarakat tentang pentingnya nilai lingkungan. Menghormati lingkungan adalah kunci sukses meningkatkan peran masyarakat di lingkungan pengelolaan kearifan lokal.

Kearifan lokal adalah sebuah warisan budaya yang terdapat pada masyarakat dan dikelola dengan masyarakat (Tamalene, 2014). Setiap masyarakat yang berada pada sebuah daerah tertentu memiliki kecerdasan tersendiri dalam menjaga kearifan lokal yang ada didaerahnya. Kecerdasan yang dimiliki masyarakat memberikan pengetahuan dalam pengelolaan kearifan lokal yang ada. Phongphit (2002) kearifan lokal sebuah pengetahuan yang berasal dari pengalaman komunitas lokal dan kebijaksaan dalam masyarakat dan individu. Kearifan lokal merupakan seperangkat pengetahuan, nilai dan norma-norma khusus yang terbentuk dari adaptasi dan pengalaman hidup dari kelompok sosial yang tinggal disebuah daerah tertentu (Mathias, 1995). Pengetahuan lokal sangat diperlukan dalam pengelolaan lahan agar optimasi yang dilakukan efisien dan berkelanjutan. Pengetahuan lokal adalah kekayaan pengetahuan dan budaya yang terus bertahan dan berkembang dalam masyarakat (Kandari, 2017). Indonesia termasuk negara yang banyak memiliki daerah-daerah yang kaya kearifan lokal.

Salah satu daerah yang memiliki kearifan lokal yang sangat penting perannya terhadap kehidupan terdapat di Desa Suban. Objek yang terdapat di Desa Suban ini adalah Lubuk Larangan Tantang Sakti. Keberadaan Lubuk Larangan Tantang Sakti dapat memberikan kegunaan yang banyak bagi masyarakat berupa air dan sumber irigasi sawah. Lubuk Larangan Tantang Sakti selain untuk memenuhi kebutuhan masyarakat sekitar, Lubuk Larangan Tantang Sakti juga merupakan sebagai penjaga DAM Suban. DAM Suban juga berperan untuk irigasi sawah Desa Suban. Untuk mencapai keberhasilan tanaman padi didaerah Desa Suban maka Lubuk Larangan Tantang Sakti harus terjaga dengan baik karena padi di Desa Suban berguna untuk memenuhi kebutuhan pokok masyarakat sekitar.

Keberadaan Lubuk Larangan Tantang Sakti tidak terlepas dari kearifan masyarakat dalam menjaga lingkungan. Dengan menjaga Lubuk Larangan Tantang Sakti maka akan tercipta keberlangsungan hidup masyarakat dalam memenuhi kebutuhan hidup sehari-hari. Lubuk Larangan tantang Sakti memiliki nilai-nilai sains yang dapat dijadikann sebagai sumber belajar. Sumber belajar yang berasal dari kearifan nokal dapat membantu mengembalikan nilai-nilai karakter yang telah memudar pada siswa. Hal ini sejalan dengan Wijaya (2018) yang menyatakan tujuan dari sistem pendidikan untuk pengembangan kognitif, pribadi siswa, sosial, dan moral. Pendidikan adalah salah satu media yang tepat yang akurat dan efektif untuk menciptakan generasi muda yang mampu menghasilkan pikiran yang ingin tahu, sikap bijaksana, berpikiran terbuka, dan konstruktif (Meliono, 2011).

Pembelajaran berbasis kearifan lokal sangat cocok untuk menunjang kemajuan dunia pendidikan. Pembelajaran berbasis kearifan lokal khususnya pada pelajaran IPA dapat lebih mempermudah pemahaman siswa, karena siswa dapat melihat sendiri berdasakan lingkungan 
sekitarnya. Kearifan lokal tersebut juga memiliki suatu potensi jika dijadikan sebagai bahan dalam proses pembelajaran. Dengan adanya pembelajaran berbasis kearifan lokal sikap dan nilai karakter dalam pembelajaran dapat dicapai dengan baik. Penerapan kearifan lokal dalam proses pembelajaran juga dinilai dapat meningkatkan pengetahuan dan keterampilan siswa dalam proses pembelajaran. Kearifan lokal berfungsi sebagai kepribadian yang baik dan pembentukan karakter terutama untuk Siswa kelas VII SMP untuk mengatur cara berpikir dan bertindak dalam kehidupan (Tanjung, 2018). Dalam hal ini dikatakan juga oleh Parmin (2015) penggunaan kearifan lokal dalam proses belajar tidak hanya menegaskan belajar konsep sains tetapi juga memperkuat national identitas yang memiliki beragam budaya.

Tujuan dari penelitian ini adalah menganalisis konsep sains yang terdapat pada kearifan lokal lubuk larangan tantang sakti dan mengintegrasikan kearifan lokal dalam pembelajaran sains. Untuk tercapai tujuan tersebut diperlukan adanya sebuah pendekatan dalam proses pembelajaran. Dari uraian diatas pembelajaran yang dapat mengintegrasikan antara SAINS dan kearifan lokal salah satunya dapat menggunakan pendekatan SETS. Pendekatan SETS (Sains Environment Technology Society) atau Sains, Lingkungan, Teknologi, dan Masyarakat merupakan satu kesatuan dalam konsep pendidikan yang mempunyai implementasi agar anak didik mempunyai kemampuan berpikir tingkat tinggi (Hidayah, 2014).

\section{Metode Penelitian}

Penelitian ini merupakan penelitian deskriptif kualitatif melalui studi entnosains (Kurniawan et al., 2019). Penelitian ini mengidentifikasi dan merekontruksi pengetahuan asli masyarakat yang berkaitan dengan lubuk larangan. Subjek penelitian ini yaitu 3 orang tokoh masyarakat Desa Suban dan 2 orang ahli pendidkan sains. Instrumen dalam penelitian ini berupa lembar observasi, wawancara dan dokumentasi. Prosedur pengumpulan data terdiri dari 4 tahap yaitu observasi awal di lokasi lubuk larangan tantang sakti, wawancara dengan tokoh masyarakat yang mengatahui sejarah dan makna lubuk larangan, observasi lanjut serta wawancara dengan ahli pendidikan sains. Uji keabsahan data dilakukan dengan triangulasi teknik yaitu pengumpulan data melalui observasi, wawancara dan dokumentasi.Analisis data dilakukan secara deskritif kualitatif untuk merekontruksi pengetahuan asli masyarakat menjadi pengetahuan ilmiah dan mengintegrasikan dalam pembelajaran sains (Sumarni et al., 2017).

\section{Hasil dan Pembahasan}

Provinsi Jambi memiliki 197 lokal lubuk larangan yang tersebar di 11 Kabupaten/Kota. Salah satu lubuk larangan terletak di Desa Suban Kecamatan Batang Asam. Kabupaten Tanjung Jabung Barat. Lubuk Larangan Tantang Sakti merupakan sebuah tradisi yang dibuat oleh masyarakat setempat untuk menjaga kelestarian ekosistem air dan ikan yang hidup didalamnya. Lubuk Larangan sungai tantang memiliki hulu sungai di Taman Nasional Bukit Tiga Puluh. Lubuk larangan Tantang Sakti memiliki larangan untuk tidak melakukan penangkapan ikan sampai dengan waktu yang telah ditentukan. Larangan tersebut telah disahkan dari mulai dibuatnya Lubuk Larangan Tantang Sakti. Lubuk Larangan Tantang Sakti sudah terbentuk \pm 5 tahun. Lubuk Larangan Tantang Sakti dapat dilihat pada Gambar 1 . 


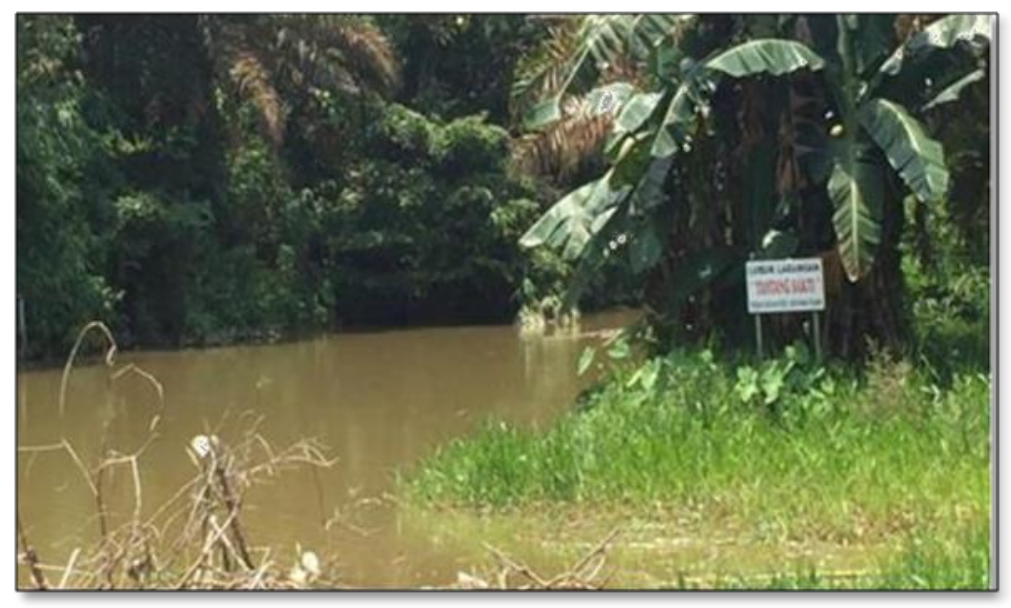

Gambar 1. Lubuk Larangan Tantang Sakti

Keberadaan sungai Tantang dimanfaatkan masyarakat di Desa Suban yang pertama sebagai sumber air, yang kedua sebagai irigasi untuk pengairan sawah di Desa Suban. Sawah yang ada di Desa Suban oleh masyarakat tetap dijaga kelestariannya meskipun Desa ini berada ditengah kepungan perkebunan sawit yang tidak terbendungkan lagi. Hal ini dikarenakan adanya kesadaran masyarakat sekitar tentang pentingnya multikultural.

\section{Konsep Sains pada Kearifan Lokal Lubuk Larangan Tantangg Sakti \\ a. Kenservasi Alam}

Salah satu cara masyarakat dalam melestarikan kearifan lokal yang ada di Desa Suban dengan cara menjadikan sungai tantang sebagai lubuk larangan agar terjaga lingkungan dan ekosistem yang ada didalamnya. Lubuk Larangan Tantangg Sakti terdapat banyak jenis ikan. Lubuk larangan Tantang sakti menjadi tempat konservasi ikan kapiat/lampam (Barbonymus schwanenfeldii).

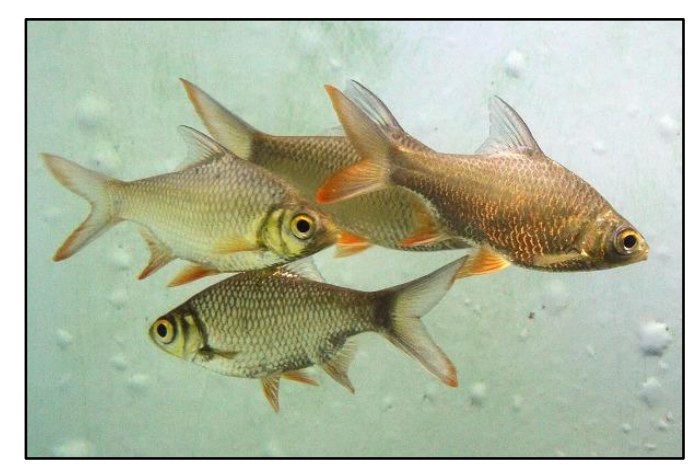

Gambar 2. Ikan kapiat/lampam (Barbonymus schwanenfeldii)

\section{b. Ekosistem}

Ekosistem adalah kesatuan yang lingkungan hidup tempat berlangsungnya hubungan timbal balik (interaksi) antara mahluk hidup dengan lingkungannya. Ekosistem dibagi menjadi dua yaitu ekosistem alami dan ekosistem buatan. Sungai Tantang merupakan salah satu contoh dari ekosistem air tawar. Sungai Tantang dikatakan sebagai ekosistem air tawar dikarenakan selinitasnya sangat rendah. Sungai Tantang termasuk dalam ekosistem alami. Sungai tantangg dapat dilihat pada gambar 3 (a). Sungai Tantangg selain dijadikan lubuk larangan juga sebagai sumber air untuk sawah Desa Suban. Sawah di Desa Suban termasuk dalam ekosistem buatan. Sawah Desa Suban dapat dilihat pada gambar 3 (b). 

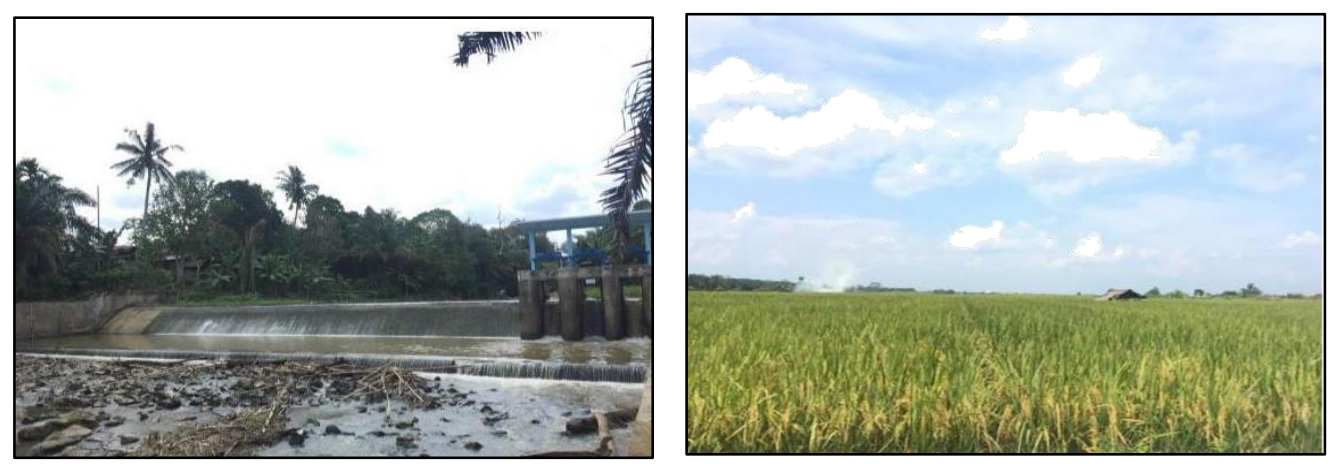

c. Fluida

Gambar 3. (a) Ekosistem Sungai Tantangg dan (b) Ekosistem sawah

Pemerintah telah membuat DAM di sungai Tantangg untuk mengontrol aliran pada. DAM ini dinamakan dengan masyarakat sekitar yaitu DAM Suban. DAM Suban bermanfaat untuk irigasi sawah Desa Suban. Pada Dam Suban terdapat konsep fluida dinamis yang dilihat dari aliran fluidanya dalam bentuk zat cair. Dalam fluida ada istilah fluida ideal dimana sifatnya inkompresibel. Dilihat dari pola aliranya, Dam Suban terdiri dari aliran tunak dan aliran laminer. Pada aliran tunak pola alirannya lebih teratur sedangkan aliran laminer pola alirannya tidak teratur. DAM Suban dapat dilihat pada gambar 4.
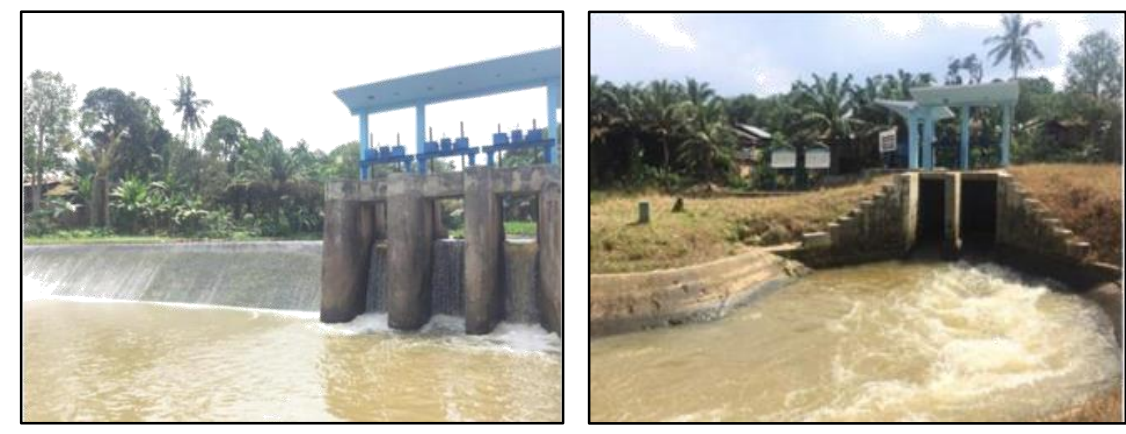

Gambar 4. DAM Suban

2. Pemetaan Kompetensi Dasar yang Terintegrasi dengan Lubuk Larangan

Berdasarkan analisis kearifan lokal lubuk larangan Tantang Sakti teridentifikasi konsep sains diantaranya konservasi, ekosistem dan fluida. Konsep sains tersebut dapat dipetakan dan diintegrasikan dengan komptensi dasar yang sesuai. Hasil pemetaan kompetensi dasar IPA dan Fisika ditunjukan pada tabel 1.

Tabel 1 Pemetaan KD pada objek kearifan lokal Lubuk Larangan Tantang Sakti

\begin{tabular}{|c|c|c|c|}
\hline \multicolumn{2}{|r|}{ Kompetensi Dasar } & Materi & Jenjang \\
\hline 3.7 & $\begin{array}{l}\text { Menganalisis interaksi antara makhluk hidup dan } \\
\text { lingkungannya serta dinamika populasi akibat } \\
\text { interaksi tersebut. }\end{array}$ & $\begin{array}{l}\text { Ekosistem sungai tantang } \\
\text { dan ekosistem sawah }\end{array}$ & Kelas VII SMP \\
\hline 3.8 & $\begin{array}{l}\text { Menganalisis terjadinya pencemaran lingkungan } \\
\text { dan dampaknya bagi ekosistem. }\end{array}$ & $\begin{array}{l}\text { Konservasi ikan } \\
\text { kapiat/lampam di Lubuk } \\
\text { larangan tantang sakti }\end{array}$ & Kelas VII SMP \\
\hline 3.3 & $\begin{array}{l}\text { Menerapkan hukum-hukum fluida statik dalam } \\
\text { kehidupan sehari-hari. }\end{array}$ & $\begin{array}{l}\text { Tekanan Hidrostatis pada } \\
\text { DAM Suban }\end{array}$ & Kelas XI SMA \\
\hline 3.4 & $\begin{array}{l}\text { Menerapkan prinsip fluida dinamik dalam } \\
\text { teknologi. }\end{array}$ & $\begin{array}{l}\text { Alira fluida pada sungai } \\
\text { tantang }\end{array}$ & Kelas XI SMA \\
\hline
\end{tabular}


Dari hasil pemetaan kompetensi dasar di atas, terlihat bahwa kearifan lokal lubuk larangan tantang sakti dapat diintegrasikan dalam pembelajaran IPA di SMP dan Fisika SMA. Hal ini sejalan dengan penelitian yang telah dilakukan oleh Bakhtiar (2016) bahwa kurikulum berbasis kearifan lokal dapat diterapkan dengan mengintegrasikan kearifan lokal dalam pembelajaran. Wulanningrum (2016) telah mengembangkan alat peraga kimia berbasis kearifan lokal yang layak digunakan.

\section{Simpulan}

Pengetahuan asli masyarakat Desa Suban tentang pengelolaan lingkungan dan ekosistem sungai merupakan kearifan local yang telah diwariskan turun temurun dalam bentuk lubuk larangan. Lubuk larangan adalah aturan tentang larangan menangkap ikan dan menjaga aliran sungai pada zona yang telah disepakati oleh masyarakat dan lembaga adat. Lubuk larangan merupakan daerah aliran sungai yang dibendung sehingga membentuk lubuk/cekungan. Masyarakat boleh menangkap ikan pada saat buka lubuk yang biasanya dilakukan 1 tahun sekali. Lubuk larangan Tantang sakti menjadi tempat pelestarian ekosistem perairan dan konservasi ikan asli (lokal). Salah satunya adalah ikan kapiat atau lampam (Barbonymus schwanenfeldii). Kebaradan lubuk larangan juga meningkatkan produktifitas pertanian masyarakat serta memudahkan masyarakat dalam memenuhi kebutuhan akan air dalam kehidupan sehari-hari. Lubuk larangan dapat diintegrasikan dalam pembelajaran IPA dan Fisika pada topik konservasi lingkungan, ekosistem, dan fluida.

\section{Referensi}

Agung, Leo. 2015. The Development Of Local Wisdom-Based Social Science Learning Model With Bengawan Solo As The Learning Source. 4(4): 2015

Bakhtiar, Afakhrul Masub. 2016. Curriculum Development of Environmental Educational Based on Local Wisdom at Elementary School. International Journal of Learning, Teaching and Educational Research. Vol. 15 No. 3, pp. 20-28

Chusorn, Pornpimon. 2014. Strategy Challenges The Local Wisdom Applications Sustainability In Schools. Procedia - Social And Behavioral Sciences 112:2014

Fahrianoor, Windari T, Taharuddin, Mar'I R, and Maryono, 2013, The practice of local wisdom of dayak people in forest conservation in south Kalimantan Indonesian, journal of wetlands environmental management issue 2354-5844 Volume 1, number 1, September 2013

Hidayah, Fitria Fatichatul.2014. Karakteristik Panduan Praktikum Kimia Fisika Bervisi-Sets Untuk Meningkatkan Keterampilan Proses Sains, Jurnal Pendidikan Sains Universitas Muhammadiyah Semarang, 2(1): 20-21

Kandari, Aminuddin Mane. Dkk. 2017. Local Wisdom as Adaptation Strategy in Suboptimal Land Management at Binongko Island, Wakatobi Indonesia. Biosci., Biotech. Res. Asia, Vol. 14 ( 1), 129-136 (2017)

Mathias, E, Recording and Using Indigenous Knowledge: A Manual. International Institute of rurar reconstruction, Cavite, Manila Thailand, 1995.

Meliono, Irmayanti. 2011. Understanding the Nusantara Thought and Local Wisdom as an Aspect of the Indonesian Education. International Journal for Historical Studies, 2 (2) 2011

Mungmachoun, Nona Roikhwanphut. 2012. Knowledge and Local Wisdom: Community Treasure. International Journal of Humanities and Social Science. Vol. 2 No. 13; July 2012

Nur. 2012. Pemanfaatan sumber belajar dalam pembelajaran sains kelas V SD pada pokok bahsan mahluk hidup dan proses kehidupan. Jesbio. ISSN: 2302-1705 
Parmin. Dkk. 2015. Skill Of Prospective Teacher In Integrating The Concept Of Science With Local Wisdom Model. Indonesian Journal of Science Education. 4 (2) (2015) 120-126

Phongphit, S., \& Nantasuwan, W. (2002). Master community plan: People research and development. Bangkok: Charoenwit.

Puspita, Diana \& Iip Rohima. 2009. Alam Sekitar. Jakarta: PT. Leuser Cita Pustaka

Sutarno. 2013. Fisikia Untuk Universitas. Yogyakarta : Graha Ilmu

Tamalene, MH, Al muhdhar, Suarsini E, Rochman F, 2014, The practice of local wisdom of Tobelo in the (togutil) tribal community forest conservation in Halmahera, Indonesia. 2014 International Journal of Plant Research, 4 (4a): 1-7 doi: 10.5923 / s.plant.201401.01

Tanjung, Fatimah, Dkk. 2018. The Development Of Local Wisdom Of Labuhanbatu Based On Teaching Material Of Descriptive Text For 7th Grade Student At Smp Negeri 1 Bilah Barat, Indonesia. International Journal Of Education, Learning And Development. 6(1): 2018

Tri Agustina, Ayu, I Gusti \& I Nyoman Tika. 2013. Konsep Dasar IPA Aspek Fisika dan Kimia. Yogyakarta: Penerbit Ombak.

Wijaya, Deni Adi. Dkk. 2018. The Attitude of socio-harmony and Local Wisdom: an Indicator of the Development of Social Tolerance of High School Students. SHS Web of Conferences 42 , 00049 (2018)

Wulanningrum, Safira. Dkk. 2016. Development Of Teaching Aids Based on Local Wisdom as a Chemistry Learning Media for Senior High School Students. International Journal of Educational Research Review. Vol 1, 2016

Kurniawan, W., Jufrida, Basuki, F. R., Fitaloka, O., \& Anwar, K. (2019). The analysis of ethnophysics process in making traditional machete in indonesia. International Journal of Scientific and Technology Research, 8(10), 1946-1949.

Sumarni, W., Sudarmin, Wiyanto, \& Supartono. (2017). The Reconstruction of Society Indigenous Science into Scientific Knowledge in the Production Process of Palm Sugar. Journal of Turkish Science Education (TUSED), 13(4), 281-282. https://doi.org/10.12973/tused.10185a 